\title{
3. Predicting Cabinet Ministers: A psychological approach
}

\author{
Michael Dalvean
}

\section{Introduction}

Why did Barry Jones not become a cabinet minister while Gareth Evans did? Was it a difference in ability, social skill or political judgment? Was it inevitable that Peter McGauran, Martin Ferguson and David Kemp would become cabinet ministers while their brothers, Julian, Laurie and Rod respectively, would not? This chapter contends that there are reasons some individuals make it to cabinet and some do not, and these differences are detectable at an early stage of an individual's career and are far more important in determining who will be a cabinet minister than the often cited 'representational' factors such as factions, States or gender. The literature on the selection of cabinet ministers in the Westminster system emphasises representational factors. The more nebulous concept of talent is usually dealt with only as a secondary or unobservable factor. Thus, the probability that an individual enters the cabinet is usually thought to be determined by her party or faction, what State she represents, as well as her age and experience. The extent to which she is likely to be promoted on the basis of talent is not considered in any more than an anecdotal fashion. This chapter will address the notion of talent and argue that there are certain cognitive factors that are far more important than any other factor cited in the literature in determining who has become a federal cabinet minister in recent years.

The approach taken is to first test for the significance of the representational factors. That is to address the negative thesis first. This approach finds that only two representational factors are statistically significant. Further, these two factors explain only a small proportion of the appointments to cabinet in recent years. I then investigate cognitive/psychological factors to explain why some people become cabinet ministers while the majority does not. I mine the parliamentary record for evidence of particular ways of thinking and perceiving the world that are associated with becoming a cabinet minister. I compare a sample of parliamentarians who have succeeded in becoming cabinet ministers with a sample which has not. This comparison finds sufficient difference between the two types of individuals to predict - with an accuracy of more than 80 per cent-who is likely to become a cabinet minister using no more 
information than their maiden speech and their educational background. In other words, the way an individual thinks, as revealed by what he has studied and what he says in his first speech, is a better indicator of his or her probability of becoming a cabinet minister than any factor such as party/faction, gender, State of origin or age.

\section{Representational Factors}

What is a representational factor? In this chapter a representational factor is defined as one that is generally considered important to reflect the make-up of parliament. For example, when an election leads to a change in the balance of State representation of a party, there is often pressure on the leader to increase the representation in cabinet of the States whose representation in parliament has increased and to decrease the representation of those States whose parliamentary representation has decreased. Similarly, as factions grow in size, it is expected that the representation of that faction should grow in cabinet. Similar arguments are mounted for gender, house (House of Representatives [HOR] versus the Senate) and, in the Coalition, the representation of the Liberal Party vis-a-vis The Nationals. Also included in the representational calculus are the average age and experience of members of cabinet. These two differ from the other representational factors in that it is accepted that the experience and age of cabinet should not necessarily mirror the average age and experience of parliament. The leader is justified in creating a cabinet that is experienced but she may also be under pressure to ensure that there are periodic infusions of 'new blood'.

With these considerations in mind, we can create a list of representational factors that is reasonably comprehensive in terms of the issues the leader faces. They are

- age

- experience

- State/Territory

- gender

- party (Liberal Party/National Party) or faction (left, centre/unaligned, right)

- house (HOR/Senate).

One of the most direct ways of testing the influence of representational factors on the probability of any individual's being a cabinet minister (CM) is to take a cross-section of a parliamentary party at a given time and see if we can discern a relationship between the parliamentary proportions and cabinet proportions with respect to each representational factor. 
Let us consider April 1996 just after the Coalition won the federal election, when Prime Minister John Howard needed to select his first cabinet. At that time there were 129 Coalition members of the Australian Parliament, of whom 15 were CMs. A breakdown of all representational factors is presented in Table 3.1.

\section{Table 3.1 Representational Factors for the Coalition, April 1996}

\begin{tabular}{|c|c|c|c|c|c|c|c|c|c|c|c|c|}
\hline Senate & Female & Vic. & NSW & Qld & Tas. & SA & WA & ACT & NT & NP & Av. age & Av. exp. \\
\hline 35 & 23 & 27 & 34 & 29 & 7 & 16 & 13 & 1 & 2 & 23 & 48.6 & 6.6 \\
\hline
\end{tabular}

On the face of it, the fact that more came from New South Wales (34) than Tasmania (seven) should translate into a greater number of cabinet ministers for the former; however, these data do not indicate how each of the representational factors influences the probability of any given individual's being a CM. We know that the general probability for a given member of the Coalition is $15 / 129=$ 0.12. But does coming from Victoria increase or decrease an individual Coalition member's probability? What about being fifty-two and having 10 years' experience? In order to answer these questions, consideration must be given to the characteristics of the entire cohort of 129 Coalition members along with all the characteristics in Table 3.1 simultaneously. But even this is not sufficient because it would only provide a snapshot for April 1996. What needs to be determined is whether there is a general trend towards rewarding particular States, parties, and so on. To do this, the study needs to evaluate several crosssections over several periods.

I therefore take five cross-sections of the Coalition parliamentary party as it existed at the first parliamentary session for 1996, 1999, 2002 and 2005, and the start of 2007 (which reflected the reshuffle that took place in the lead-up to the November 2007 election) - a total of 192 individuals. In this way, any patterns in the way cabinet posts were awarded will be captured. To indicate the data structure that this involves, in Table 3.2 I draw out the data for two of the individuals in the cohort.

Judith Troeth is a Senator and thus scores one for this variable, while Tony Abbott is not, and receives zero. Similarly, Troeth receives a one for the variables 'Fem.' (Female) and 'Vic.' (Victoria), while Abbott receives a one for 'NSW'. Neither individual receives a scoring for National Party (NP) as they both belong to the Liberal Party. The age and parliamentary experience display the age and length of time in parliament respectively of each individual in the given years. Finally, the ' $\mathrm{CM}^{\prime}$ ' column shows the $\mathrm{CM}$ status of the individual at the time the cross-section was taken. Abbott was promoted to CM in 2000 so he is coded as zero for 1996 and 1999 and thereafter as one. Troeth was not a CM in the years listed so receives a coding of zero for all years. 


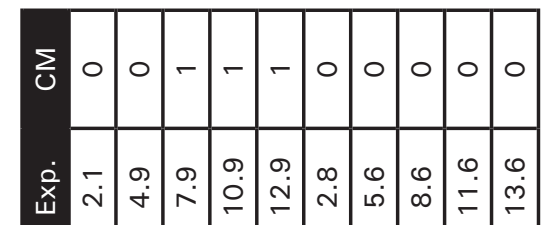

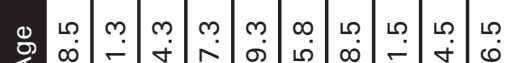

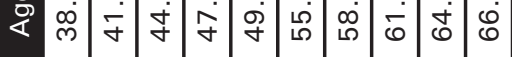

$\begin{array}{lllllllllllll}\frac{n}{2} & 0 & 0 & 0 & 0 & 0 & 0 & 0 & 0 & 0 & 0\end{array}$

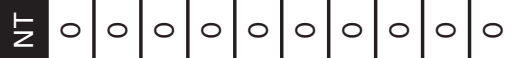

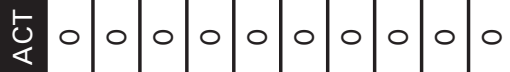

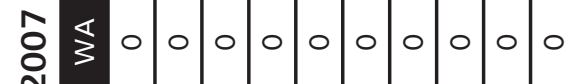

N

ตั

근

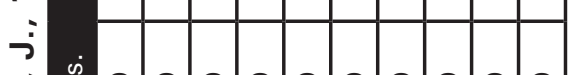

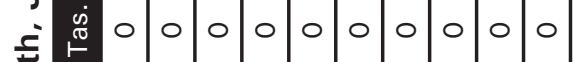

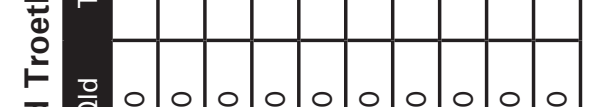

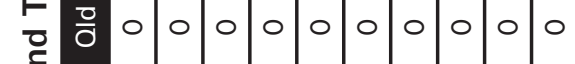

กั

\begin{tabular}{l}
3 \\
$\dot{1}$ \\
\hline
\end{tabular}

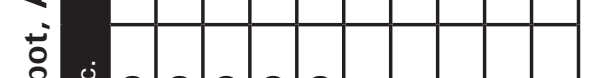

$\begin{array}{lllllllllllllll}\frac{0}{2} & \dot{0} & \circ & 0 & 0 & 0 & 0 & 0 & - & - & - & - & - & -\end{array}$

弚

के

홍

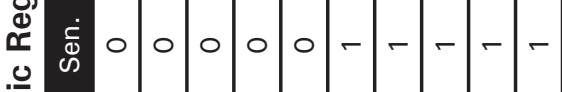

帒

:

흔

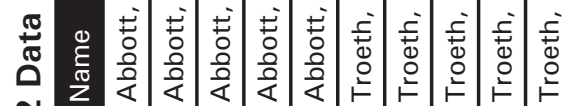

N

m $\frac{2}{x}$

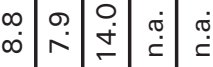

ळ)

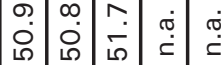
ष

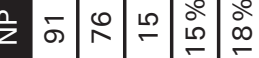

々

の $の ~ \circ \stackrel{\circ}{\circ}$

E

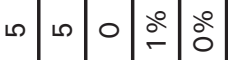

$\frac{\pi}{3}$

N

ॐ

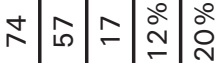
ํㅗㅇ

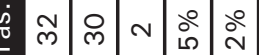

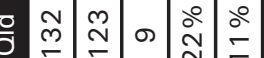

क्षे

उ (1)

i

$\because \stackrel{m}{\sim} \stackrel{\sim}{\infty}$

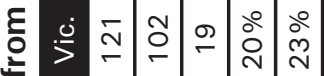

苋

$\stackrel{\frac{0}{\sigma}}{2} \stackrel{\circ}{\circ} \stackrel{\circ}{\circ} \stackrel{\circ}{\sim}$

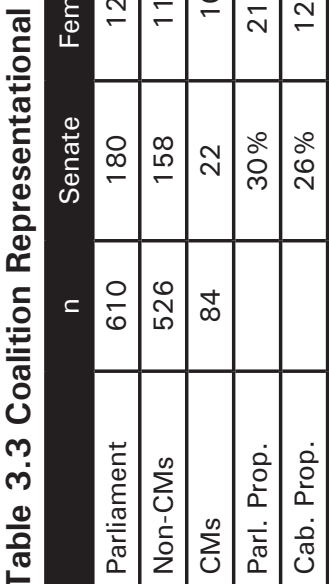


All 192 individuals who were members of the Coalition for the period 1996-2007 were coded using these principles. Individuals who belonged to the Coalition for any part of that time were included in the analysis only for as long as they were in the Coalition. Individuals who changed party within the Coalition, State or house were coded accordingly at each point.

With the data from five cross-sections a trend emerges, explaining the long-term structure of the Parliament as well as that of the cabinet. Table 3.3 summarises the data from the five pooled cross-sections.

The pooled data involving 192 individuals provide 610 observations over the five cross-sections. Non-cabinet ministers made up 526 observations, while there were 84 cabinet minister observations. Thus, the overall probability of any individual's being a CM was 14 per cent $(84 / 610)$. Taking each of the different representational factors, however, we find varying results. Over the whole period, the Senate made up $180 / 610=30$ per cent of Parliament, but its cabinet proportion was only $22 / 84=26$ per cent, demonstrating a slight underrepresentation. Females were systematically under-represented in cabinet: female representation in Parliament was 21 per cent, yet females made up only 12 per cent of cabinet. New South Wales was over-represented, with a parliamentary proportion of 27 per cent but cabinet representation of 38 per cent. Conversely, Queensland was under-represented, with a parliamentary representation of 22 per cent and a cabinet representation of 11 per cent. South Australia was significantly over-represented with a parliamentary proportion of 12 per cent and a cabinet representation of 22 per cent. Concomitantly, Western Australia had a parliamentary proportion of 12 per cent and a significantly lower cabinet representation of 6 per cent. The figures for Tasmania, the Australian Capital Territory and the Northern Territory are too small to come to firm conclusions on the basis of the raw figures.

On party representation there was close correspondence between the parliamentary proportion of The Nationals at 15 per cent and cabinet proportion at 18 per cent, reflecting the Coalition agreement that the Liberal Party will appoint NP members to cabinet at least in proportion to The Nationals' representation in Parliament. Finally, the average age of CMs (51.7 years) is almost one year older than the Parliament as a whole (50.9), reflecting the higher average experience of CMs: 14 years compared with an average of 8.8 for Parliament as a whole. The logical conclusion here is that it takes time to become experienced, hence those with more experience are older.

These figures give us a starting point for determining the influence of each representational factor on the probability of any given individual's being appointed to cabinet at any given time. The problem is that we cannot rely on them alone. Consider, for example, two phenomena that we have observed in the 
above descriptive data: the under-representation of females and a positive effect of having more experience. On the face of it there is a rather straightforward case for saying that these phenomena are independent; however, let us consider that they may be linked. The women have an average experience of 7.7 years-less than the non-CM average of 7.9 and much less than the CM average of fourteen. Therefore, in addition to any bias against women based on their gender, we must also take into account the fact that there was only a small pool of experienced women to draw from. So a certain proportion of the under-representation of women observed is due to women being relatively inexperienced in comparison with men. That is, a proportion of the under-representation of women did not occur because of their gender but because of their lack of experience. Of course, the low number of women in Parliament might be caused by gender and hence their lack of experience by gender, but once in Parliament gender does not seem to be a further factor. It is only by 'controlling' for experience that this fact emerges. Similarly, the under-representation of one State may be due to some other factor such as under-representation of members from the Senate or NP. To tease out these complex possibilities, we need to take into account all the variables that are presented in Table 3.3 simultaneously rather than individually. The way to do this is to use logistic regression with a repeated measures design.

The details of the Coalition representation factors logistic regression model is presented in Appendix 3.1A. In the Coalition model, New South Wales (the largest State) is the excluded category so the coefficients for the other States are calculated in respect of New South Wales. It should be noted that, as no ministers were drawn from the Australian Capital Territory or the Northern Territory over the period under consideration, these Territories were not included in the analysis. The following discussion summarises the results.

In the Coalition representational factors model there is no statistically significant effect of being female, a member of the NP, a senator or coming from any State other than Queensland. There is a significant $(p<0.05)$ negative effect of coming from Queensland, indicating that CMs were preferentially chosen from New South Wales as opposed to Queensland. Age is significantly ( $p<$ 0.01 ) positively associated with $\mathrm{CM}$ while age squared is negatively associated with CM. This means there is a negative quadratic relationship between age and $\mathrm{CM}$. The probability of appointment to cabinet increases up to the age of fortyseven, after which it decreases. In both models experience is significantly ( $p<$ 0.01) positively associated with CMs, while experience squared is borderline significantly $(\mathrm{p}<0.1)$ negatively associated with $\mathrm{CM}$. This provides some evidence that there is a negative quadratic relationship between experience and age with the probability of appointment to cabinet rising until 31 years' experience, after which the probability of appointment falls. 
The conclusion from the model is that there is evidence for a negative quadratic relationship between age and $\mathrm{CM}$, experience and $\mathrm{CM}$, and a negative association between Queensland and CM indicating that there was a negative effect of coming from Queensland in comparison with New South Wales. None of the other variables is significant. Thus, the majority of the representational variables is not significant.

As well as there being few variables with statistical significance, the classification accuracy of the model using representational factors is quite low. The classification accuracy is 87 per cent, which seems impressive until we realise that the baseline accuracy is 84 per cent. This represents a small improvement. The specificity of the Coalition model - that is, its ability to detect those who will be cabinet ministers - is only 26 per cent. In other words, of the $84 \mathrm{CM}$ observations only 12 actual appointments to cabinet are explicable, leaving 72 unexplained by the representational factors. The conclusion is that the Coalition models, which include all the representational factors usually cited in the literature, do not explain the bulk of cabinet appointments.

A second study was undertaken with data from the Australian Labor Party (ALP) in opposition. The problem with these data is that for most of the period the shadow ministry was not divided into a shadow cabinet and a shadow outer ministry. This division, however, was made for the period 2005-06, enabling a cross-sectional analysis for the ALP for these two years. It should be noted that this provides a sample size of 175 , which is lower than that usually required for a regression analysis of this nature. The results, thus, should be interpreted with some caution. Details of the models are provided in Appendix 3.2. The results are similar to those for the Coalition. In the ALP representational model, New South Wales is the excluded category for the geographical variables and the right faction is the excluded category for the three factions (left, right and centre/independents).

Experience is significantly $(\mathrm{p}<0.01$ ) positively associated with $\mathrm{CM}$ and experience squared is significantly negatively associated with CM. Thus, there is evidence for a negative quadratic relationship between $\mathrm{CM}$ and experience as in the Coalition model. Furthermore, Western Australia has a significant ( $p$ $<0.05)$ positive coefficient and South Australia has a borderline significant ( $p$ $<0.1$ ) positive coefficient, indicating that there was a positive effect on $\mathrm{CM}$ of coming from these States in comparison with New South Wales. Thus, the only representational factors that were significant are experience, experience squared (borderline), Western Australia and South Australia (borderline). None of the other representational factors is significant.

Furthermore, the ALP models explain very few of the actual shadow cabinet appointments. The representational ALP model has a classification accuracy 
of 79 per cent - equal to the baseline. The specificity is 25 per cent for ALP, indicating, as with the Coalition models, that these representational factors account for few actual appointments to cabinet.

Before continuing it is worth diverging from the main argument to explain how the coefficients for most of the representational factors in both parties could be non-significant when the qualitative accounts state that representational factors affect cabinet appointments. Much commentary has been devoted to the influence of factions on ALP parliamentarians' careers; intense rivalry between the States has been cited as the reason for many cabinet appointments or lack thereof; commentators accuse both the Coalition and the ALP of not adequately representing gender in Parliament. Yet the regression analysis tells a different story. It shows that the influence of most representational factors is not significant and that the effect on actual appointments is weak. How can we reconcile these two opposing viewpoints?

The best way to conceptualise the situation is to consider the effect of perfect representation. Consider a parliamentary party with 120 members from which the leader has to select a cabinet of twelve. The probability of being a CM for any individual is $1 / 10$. We will now divide the party into three factions (we could use States, gender or any other representational factor-the concept is exactly the same). Faction A has 30 members, Faction B has 20 and Faction C has seventy. The leader needs to maintain factional balance so she must ensure that the 12 members of cabinet are drawn from each faction in proportion to the faction's numbers. Thus three members are drawn from Faction A, two from Faction B and seven from Faction C. What is an individual's probability of being a CM if he or she is from Faction $\mathrm{A}$ ? The answer is $3 / 30=1 / 10$, for Faction $\mathrm{B}$ the probability is $2 / 20=1 / 10$, and for Faction $C$ the probability is $7 / 70=1 / 10$. For all factions, the probability of being selected to become a member of cabinet is $1 / 10$ - exactly the same as the probability for a member of the parliamentary party without taking factions into account. In other words, if the leader draws CMs from the factions in the same proportion as their numerical representation, being a member of any faction does not alter the probability of being a CM no matter how numerous its members or how 'powerful' it is relative to the other factions.

What this indicates is that, in a parliament where the leader draws cabinet members from the representational factors in perfect proportion to their representation in parliament, there is no statistical effect of the representational factor. There is only a statistical effect where there is bias in the leader's choice. Let us consider how this explains the results in the Coalition model. The coefficients for the majority of representational factors except age, experience and Queensland are not significant because leaders tend to draw CMs instantiating the various representational factors (excluding age, experience and 
Queensland) in close proportion to their numerical representation in Parliament. There is a statistically significant negative effect of coming from Queensland (in comparison with New South Wales). This indicates that perfect representational practices were not observed in relation to these States. There is also a statistically significant negative quadratic effect of age and experience, indicating that the leader did not draw CMs from Parliament in such a way as to mirror in cabinet the age and experience structures of Parliament.

The same is largely true for the ALP in opposition. There is good evidence for a negative quadratic relationship between experience and CM. There is also evidence for a positive association bias towards drawing CMs from South Australia and Western Australia in comparison with New South Wales. These statistical effects indicate bias in that the leader is departing from perfect representation.

\section{Summary}

I have examined the factors that are usually cited as important for explaining cabinet appointments. I found that in both the ALP and the Coalition there was some evidence for a quadratic relationship between experience and CM and, in the case of the Coalition, between age and CM. There was also a statistically significant negative effect in the Coalition model of coming from Queensland. In the case of the ALP in opposition, there was some statistical evidence that coming from Western Australia and South Australia was positively associated with CM in comparison with coming from New South Wales. Beyond these effects, no statistical effect was observed. In other words, the majority of the representational factors were not significantly associated with CM. Furthermore, in both the ALP and the Coalition models the explanatory power was small.

In order to explain these counterintuitive findings, I explained that the statistical effect of the representational factors occurs only if there is a bias. Thus, where the leader draws cabinet members from the representational factors in Parliament in proportion to their representation in Parliament, there will be no statistical effect of the representational factors. The fact that there is a statistical effect of some of the States, age and experience indicates that the leader is exhibiting some bias in relation to these factors; however, as the classification accuracy shows, even though there is some statistical bias in respect of some representational factors, the overall explanatory effect of these factors is not great. In short, the representational factors do not explain the majority of appointments to cabinet.

So, there being very little evidence for the explanatory power of representational factors, we must seek an entirely different method of determining who becomes a cabinet minister. 


\section{The Sample}

The cohort from which the model was created consists of all ALP and Coalition parliamentarians who were in Parliament at any stage between the federal elections of April 1996 and November 2007.

The modelling process was conducted separately for the Coalition and the ALP. The reason for this was that the accuracy achieved by splitting the analysis in this way was substantially higher than the accuracy achieved by undertaking a combined analysis. This is good evidence that, despite some similarities in the qualities that lead to cabinet appointments in the Coalition and the ALP, there are also significant differences.

Individuals were divided into CMs and non-CMs. The group of non-CMs was made up of backbenchers (BBs), junior ministers (JMs) and parliamentary secretaries (PSs). Individuals were coded as BB, PS, JM and CM according to the highest executive level each achieved in government. For example, Coalition member Malcolm Turnbull had been both a PS and a CM; he was defined as a CM because this was the highest executive level he had achieved while the Coalition was in power.

For the Coalition there were 192 subjects. Of these, 34 reached the position of $\mathrm{CM}$ at some stage in their career. The remaining 158 comprised 33 JMs, 25 PSs and 100 BBs. For the ALP sample there were 147 subjects. Of these, 34 were CMs, 17 JMs, 10 PSs and 86 BBs.

In order to create logistic regression models, parliamentarians were divided into two categories: the case group, which consisted of the CMs; and the control group, the non-CMs. Details of the potential case and control groups for both the Liberal-National Party Coalition (LNPC) and the ALP are presented below.

$\begin{array}{lcc} & \text { LNPC } & \text { ALP } \\ \text { Case group (cabinet ministers) } & \\ \text { CMs } & 34 & 34 \\ \text { Total in case group } & 34 & 34 \\ \text { Control group (non-cabinet } & \text { ministers) } \\ \text { JMs } & 33 & 17 \\ \text { PSs } & 25 & 10 \\ \text { BBs } & 100 & 86 \\ \text { Total in control group } & 158 & 113\end{array}$

There is, however, a problem with this study design. Many of the BBs were not in Parliament for long enough to demonstrate executive potential. In general, there is a lag time before an individual is appointed to a CM position. For members 
of the Coalition who entered Parliament at the 1996 election, those who became CMs took an average time of approximately 5.5 years with a standard deviation of 2.5 years. By including all the BBs in the groups outlined above, we would be including members who were in Parliament for terms considerably shorter than this. These people might have been appointed to CM positions had they had the time in Parliament to demonstrate their ministerial ability. This problem was addressed by excluding individuals who were BBs and who were in Parliament for less than 10 years. The idea here is that an individual who was a BB who had been in Parliament for more than 10 years was by now clearly unlikely to be appointed to a CM position.

A related problem is that where a BB's party may have been in opposition during the bulk of his or her parliamentary career it is possible that, had that party been in government, the BB might have achieved an executive position. In order to reduce the probability of this type of error, those BBs who held any kind of shadow ministerial position in opposition were also excluded. This leaves a cohort of BBs who are truly BBs in that they were not considered to have any executive potential in either a government or a shadow ministry.

The restriction on the definition of BBs therefore reduces the number of BBs in the models to 36 in the LNPC model and 21 in the ALP model. Thus, the final figures for the control groups are as follows.

$\begin{array}{lll} & \text { LNPC } & \text { ALP } \\ \text { JMs } & 33 & 17 \\ \text { PSs } & 25 & 10 \\ \text { BBs } & 36 & 21 \\ \text { Total in control group } & 94 & 48\end{array}$

The control groups thus represent a good spectrum of ministerial ability to compare with the case groups. The BBs represent those who have demonstrated no ability to function in any kind of executive role; PSs have demonstrated a bare minimum of ministerial potential; JMs have demonstrated ministerial potential but not sufficient to warrant a promotion to cabinet.

\section{The Independent Variables}

The basic variable used in this exercise consists of a dummy variable for legal education as well as a number of linguistic variables derived from the maiden speech.

It makes sense that an individual's cognitive style and way of looking at the world are influenced by his or her education and therefore it was considered important 
to account for education in the model. Initially, several dummy variables for various types of education were tried in the model. These included dummies for having a tertiary education of any kind, having a technical/scientific/medical education, having an arts or law degree and having a postgraduate degree.

The linguistic variables were derived from a computer-aided text analysis of the maiden speech of each individual parliamentarian in the samples. The idea of using maiden speeches is based on the assumption that there is a quality that leads to cabinet membership that can be extracted from the speech acts of members and that the maiden speeches of members are a good source for these speech acts because they all occur in a similar manner, format and context. Another benefit of maiden speeches is that they tend to cover general topic areas. Most include a biographical sketch of the member and reference to the characteristics of her electorate. They tend to contain discussion of general economic questions as well as specific issues that affect the member's electorate and particular subjects that interest the member. Finally, many speeches include thanks to people who have helped the member get into Parliament.

It is important to compare members' speaking on a broad spectrum of topics. Let us consider what might occur if we did not do this. Consider a speech by a member representing her party's position on a concrete area such as taxation policy and a speech by another member representing her party's position on a more abstract area such as human rights. If we were to compare these we might conclude that the first member was more concrete in outlook while the latter was more abstract. In fact, it is the subject matter that is leading to the distinction not the cognitive style of the member. In order to avoid this problem we need wide-ranging speeches, and the maiden speech is ideal for obtaining a speech sample that shows how the member addresses a relatively broad spectrum of subjects.

It should be stated at this point that I do not suggest there is a causal connection between the speech and the subsequent career trajectory. Rather, the maiden speech is a marker of particular cognitive characteristics. Because it is essentially on topics the member chooses, the maiden speech is likely to be highly indicative of what she or he considers important. As such it is likely to be indicative of what the member thinks about and, more importantly, how the member thinks. The maiden speech instantiates a general set of psychological/cognitive characteristics of the individual; it is contended that these characteristics are what lead to cabinet appointment. Thus it makes no sense to say that a member might change the content of their maiden speech in an attempt to change their career trajectory. A good analogy here is that of a blood test that is used to assess the risk of a heart attack. The presence in high proportions of low-density lipoprotein does not cause a heart attack; however, it is a marker indicative of a syndrome, the presence of which increases the risk of having a heart attack. I 
do not contend that the presence of certain verbal characteristics as revealed in maiden speeches causes selection for cabinet; however, they may be related to a cognitive 'syndrome', the presence of which significantly increases the 'risk' of being chosen as a CM.

One other issue of importance is whether the maiden speech consists of the member's own thoughts. This can be answered by pointing out that maiden speeches are highly likely to be written by the members themselves. Neophytes are less likely to have the resources of those members, such as ministers, who regularly have their speeches written by others; however, in rare cases where a speech is written by another, it is highly likely to reflect the thinking style of the member, and the member will vet the content and style before delivery. The 'ghost writer' problem has been given careful consideration in text-analysis literature. Suedfeld and Rank (1976) found that the spontaneous speech utterances of a selection of 19 revolutionary leaders had the same level of linguistic complexity as prepared speeches, indicating that both the individual's actual speaking style and the speeches they had had prepared for them reflected the same underlying cognitive style. This indicates that the vetting by the speaker of the style and content of prepared speeches is highly likely to ensure that the verbal characteristics in the prepared speech closely mirror those of the speaker's actual verbal characteristics. Winter (1987) explained why presidential inaugural addresses, usually written by a speechwriter, could nevertheless be reliably used to derive 'motive scores' of individual presidents:

When formal prepared speeches are scored, it is natural to ask whether the results reflect the motives of the president or those of the speech writers. There are, however, several reasons for believing that this is not an important problem. First, any good speech writer knows how to produce words and images that feel appropriate and comfortable to the presidential client. Second, before a speech as important as the first inaugural address, presidents spend a good deal of time reviewing and changing the text, paying special attention to the kinds of images that are coded in the motive-scoring systems. For example, the various drafts of President Kennedy's inaugural address show insertions and deletions of scorable imagery, in Kennedy's own handwriting. Many speeches in the Eisenhower Library archives show the same. Thus, although the words may have originated from many sources, in the end an inaugural address probably says almost exactly what the president wants it to say. (Winter 1987, 198)

There is no reason to think that these considerations do not apply to the maiden speech of Australian parliamentarians. After all, maiden speeches provide the first opportunity for Australian parliamentarians to introduce themselves to Parliament. Hence, it seems reasonable that, if it were written by a 'ghost' the 
parliamentarian would still spend considerable time and effort to ensure that it represented what she wanted to say or wanted to project in terms of message and persona.

It should be stressed that, for the purposes of the construction of the models, a maiden speech is defined as the first speech given by the individual in Federal Parliament. Thus, for those parliamentarians who had experience in State parliaments, the maiden speech in the Federal Parliament was used. For those parliamentarians who had lost their seats and then were later re-elected the maiden speech was taken as the first speech given in the first period in Parliament.

The most technically demanding aspect of the model-building process is the transformation of the maiden speeches into linguistic variables. This was done with the text-analysis program Linguistic Inquiry and Word Count (LIWC). Pennebaker and King $(1999,1296)$ state that 'one of the most daunting problems in assessing linguistic styles is in deciding on the appropriate dimensions of language and, once selected, determining the best unit of analysis'. Their solution is to concentrate on the 'how' rather than the 'what' of discourse. The idea here is that the way people express themselves provides data about them. This is the basis of the LIWC approach.

The problem with many attempts to use text data to create a profile of the speaker is that a theoretical stance is taken about underlying constructs such as personality traits or motives and it is assumed that these constructs are manifested in the speaker's narratives. This is essentially the approach taken by Emrich et al. (2001) and House et al. (1991). To avoid having to rely on theoretical constructs, Pennebaker and King developed the Linguistic Inquiry and Word Count program. The difference between LIWC and other text-analysis methods is that the categories were determined empirically based on how words are actually used. This is quite different from most other word-count strategies, which make assumptions about the relationship between word categories and what they reveal about underlying psychological characteristics. For example, Martindale's (West et al. 1983) regressive image method breaks a large sample of common words into 'concept' words as opposed to sensory words, and holds that those who use concept words are less aligned with the primordial impulses than those who use sensory words. Thus, to 'travel' involves a concept because it does not mention the means of locomotion. In contrast, to 'walk' is a sensory word because we can imagine the sensations associated with walking. Martindale and Dailey (1996) used this method to show that there is a link between high creativity and higher use of sensory words. Another theoretical approach is that of Herman (2003), which holds that the use of words high in certainty is associated with the construct of conceptual complexity. The theoretical approaches to text analysis are similar in that they posit an 
underlying psychological construct and use text analyses based on word-count strategies to tap the construct. In a CM selection problem we have little idea as to what is important.

In contrast with the theoretical approaches, LIWC is based on the empirical analysis of language use. The starting point with LIWC is the dictionary and its division into sub-dictionaries or categories. The original categories were chosen because the program's originators wanted to develop a list of words associated with common behavioural and cognitive processes and activities. These processes and activities became the 72 basic categories used in LIWC. They included 'negative emotion', 'affect', 'leisure', 'work', 'family', 'social activities' and 'psychological processes'. For each of these basic categories the developers sought a list of associated words. For example, the psychological processes category words were developed from the Positive Affect Negative Affect Scale (Watson et al. 1988, cited in Pennebaker et al. 2007), Roget's Thesaurus and standard English dictionaries. From these sources the list of words associated with 'psychological processes' was developed. The initial set of words was then assigned to other categories according to their cognitive content. Thus, the word 'angry', as well as going into the 'psychological processes' category, went into the 'anger', 'negative emotion' and 'affect' categories. An important aspect of the 72 basic categories is that there is a hierarchical structure. In determining the basic cognitive and behavioural categories it was necessary to account for different levels at which each word could be categorised. For example, it would not be sufficient to categorise the word 'offensive' as 'affect'. A separate, more detailed category was required to capture the negative connotations of the word. Thus, hierarchical categories were added so that each word could be categorised at a high order and one or more lower-order specific categories. 'Offensive', for example, is categorised as 'affect', at the highest order and, at progressively lower orders, as 'negative emotion' and 'anger'.

It should be noted that there was no more theory involved in the process of creating the LIWC word categories than knowledge of how the words are used in Standard English. The lack of any theoretical structure in the process is evident in that the procedures used to vet the words included in each category were entirely empirical. To determine which words should be included in each category, an agreement of at least two out of a panel of three judges was required; otherwise the word was dropped. The resulting categorisations were then subjected to the same process by a panel of three different judges.

Since the first version of LIWC came out in 2001 there have been modifications. The 2007 version has 80 categories. Sixty-eight of these are word categories while the remaining are structural and include such measures as words per sentence, commas and long words (greater than six letters). Parts of speech have appropriate categories, enabling words to be classified according to person, 
tense, and so on, as well as by cognitive content. The total number of words recognised by the 2007 version is approximately 4500 including word stems. From a large sample of written and spoken language across multiple genres, Pennebaker et al. $(2007,10)$ found that 82 per cent of the words used were included in the 2001 LIWC dictionary. Thus, there is good evidence that the LIWC dictionary captures a large proportion of words used in spoken and written English.

The running of LIWC is straightforward. LIWC works by comparing the words in the target text with the words in the various pre-established category dictionaries. If a word in the target text is one of the words or word stems in one of the category dictionaries, the appropriate word categories are incremented. The word 'family', for example, falls into the categories of 'social', 'family', 'leisure' and 'home'. If 'family' occurred twice in a text of 200 words, each of the 'family', 'leisure' and 'home' categories would be incremented by 2/200 =1/100. Final output for all variables except the 'word count' variable is expressed as a percentage of the total number of words in the text.

The utility of LIWC in text analysis has been demonstrated across a substantial number of domains. Tausczik and Pennebaker (2010) list 121 studies using LIWC for text analysis since 2001 when the first version became commercially available. These include applications to political discourse. LIWC was used to analyse television interviews with Democrat presidential candidates in the 2000 and 2004 US elections. It was found that John Kerry and John Edwards used similar rates of 'positive emotion' words whereas Kerry used higher rates of 'negative emotion' words. A comparison between Kerry and Al Gore found that they had very similar linguistic styles. In particular, they had very similar levels of pronoun usage and insight and cognitive words. Edwards' interviews were statistically significantly different from both Kerry's and Gore's on these measures. Hirst et al. (2010) analysed the Hansard of the Canadian Parliament in two periods over which the government had changed. They found that the party in government uses more 'positive emotion' words while the party in opposition uses more 'negative emotion' words. Yu et al. (2008) used LIWC to determine whether it was possible to use text analysis to classify opinions on topics in US congressional debates as 'for' or 'against'. The idea of such applications is that it should be possible to determine whether a speaker supports or opposes a topic under discussion on the basis of markers such as positive and negative emotion. They found that most congressional debate involves very low levels of sentiment and concluded therefore that using sentiment-laden adjectives was not sufficient for opinion classification in political speech. Niederhoffer and Pennebaker (2002) used LIWC to analyse the official transcripts of the Watergate tapes. They were looking for evidence that in dyadic conversation the words of one speaker will co-vary with the words of the other. The idea 
behind this is that the words used by the first speaker prime the second speaker to use particular words. This 'synchrony' is the verbal equivalent of physical synchrony in which interlocutors will mirror each other's body language. They found support for the language-synchrony hypothesis at both the turn-by-turn level and the overall conversational level.

The LIWC approach constitutes the majority of the linguistic variables in both the ALP and the Coalition models; however, it was found in preliminary modelling that the accuracy of one of the models could be improved by including another set of variables from the maiden speeches. As only one of these variables was significant in the model-building process, this analysis and discussion are confined to this variable. The variable comes from the results of Paivio et al. (1968) (hereinafter PYM). In this study a selection of 925 concrete and abstract English nouns was measured on a number of linguistic scales. One of the scales was the ease of definitions. For each word in the sample, subjects were asked how easy it was to define on a scale of one to seven, with seven being easiest to define. Out of the sample of 925 words the word that was easiest to define was 'baby' (score $=6.79$ ) while the hardest was 'gadfly' (score $=1.92$ ). Paivio et al. (1968) found that the number of definitions a word has is correlated with other linguistic variables such as the concreteness of a word, the age at which it is acquired and the 'imagability' of the word - that is, how hard it is to imagine the object depicted, the idea being that abstract nouns are harder to imagine than concrete nouns.

The PYM scores on 925 common nouns were used to create a proxy for the average number of definitions of the words used in maiden speeches. The procedure was as follows. The first step was to identify, for each speech, which of the 925 words in the PYM sample were present. The average for these was then calculated. Consider, for example, the sentence 'The baby ridiculed the gadfly's umbrella'. In this sentence the words 'the' and 'ridiculed' are not in the PYM sample, so they are ignored. The words 'baby', 'gadfly' and 'umbrella' are in the sample with scores of 6.79, 1.92 and 6.04 respectively. As the sentence contains three words from the PYM sample, the 'def' score for the sentence is calculated as follows: $(6.79+1.92+6.04) / 3=4.92$. If 'baby' appeared twiceas in the sentence 'The baby ridiculed the baby gadfly's umbrella' -its score would be included twice, so the calculation is: $(6.79+6.79+1.92+6.04) / 4=$ 5.39. In this way we get a proxy for the average number of definitions of words used in each speech. It is only a proxy because it is based on a 925-word sample; however, as we shall see, this variable is useful in the modelling process. 


\section{The Modelling Process}

As the problem is essentially one of classification, two traditional modelling processes were considered: logistic regression and discriminant analysis. Inspection of the data revealed that some of the variables were not normally distributed. Furthermore, there was evidence of some nonlinearity between the dependent and independent variables. Discriminant analysis assumes a normal distribution of variables and linear association between independent and dependent variables while logistic regression does not. Thus, logistic regression was deemed more appropriate than discriminant analysis.

In order to fit the best possible model, forward stepwise regression was used. This procedure involves using an algorithm that selects the independent variables from a large selection of possible independent variables. The algorithm selects those variables that are best at predicting the dependent variable. All 80 LIWC variables were initially considered for inclusion, as were linguistic variables based on the Paivio et al. (1968) study and the education variables. Several LIWC variables, such as 'swearing' and 'parentheses', were excluded from the analysis. Swearing was excluded because of problems with the recognition of words in context (this is a problem with the word-count strategy in general). For example, the software was unable to distinguish between the use of the word 'bloody' in the context of a description of a battle and its use as an expletive. The punctuation category 'parentheses' was excluded because Hansard changed its style on parentheses during the period over which the sample was taken. The earliest speech in the sample is from Ian Sinclair, who delivered his maiden speech in 1961. At that time, if the member mentioned another member by his title, the Hansard transcribers did not insert the name of the mentioned member's constituency in parentheses. This practice was adopted significantly later, meaning that the use of parentheses is not consistent across the sample of speeches.

Untransformed independent variable data were used in the initial stages of model development. The preliminary models created using these data had high predictive power but, due to the non-normal distribution of the data, the confidence intervals of several of the variables were very wide. To remedy this problem, highly non-normal variables were transformed into quintiles. Thus, cases falling in the first quintile were designated one, those falling in the second quintile were designated two, and so on up to the fifth quintile. Variables transformed in this way are designated with a terminal ' $Q$ '. Finally, all variables were standardised to make interpretation of the coefficients easier. This had no substantive influence on the model or its interpretation. 


\section{The Coalition Model}

Variables that were significant in the Coalition model were as follows.

- Dummy variable for legal education: this denotes individuals who have had a legal education, which academically entitles them to practise law. It is significantly positively associated with CM.

- Spatial words: this is the rate of use of spatial terms such as 'over', 'up' and 'around'. This variable is significantly positively associated with CM.

- Certainty words: this is the rate of use of words denoting certainty such as 'absolute', 'never' and 'exact'. This variable is significantly positively associated with CM.

- Apostrophe occurrence: this variable measures the rate of occurrence of apostrophes. As we will see below, the use of apostrophes in Hansard is a proxy for references to third parties. This variable is significantly positively associated with CM.

- Feeling words: these are words that denote sensations associated with touch such as 'hand', 'flexibility' and 'rough'. These terms are significantly positively associated with CM.

- Second-person pronoun (you): this is an index of the use of the second-person pronoun. It is significantly negatively associated with CM.

- Colon occurrence: this is the rate of occurrence of colons in the texts of speeches. There are several situations in which colons are used in Hansard. One of these is when recording an elaborate quotation and this usage constitutes the majority of occurrences in the maiden speech sample.

Two of the variables in the Coalition model are not significant

- all punctuation: this is an index of the amount of punctuation used in a speech and can be seen as a proxy for linguistic complexity; this is negatively associated with $\mathrm{CM}$ but is not significant $(\mathrm{p}=0.139)$

- definitions: this, as we saw above, is a proxy for the average number of definitions of the words used in speeches and can be taken as being some indication of the sophistication of the vocabulary used; this variable is negatively associated with CM but is of borderline significance ( $p=0.068)$; however, its inclusion added to the predictive accuracy of the model. 
Parameter estimates for all variables in the Coalition model are presented in Table 3.4.

Table 3.4 Parameter Estimates for the Coalition CM Model

\begin{tabular}{|c|c|c|c|c|c|c|}
\hline & B & S.E. & Wald & df & Sig. & $\operatorname{Exp}(B)$ \\
\hline spaceQ & -0.807 & 0.352 & 5.264 & 1 & 0.022 & 0.446 \\
\hline feelQ & 0.941 & 0.340 & 7.654 & 1 & 0.006 & 2.561 \\
\hline certain 0 & -0.864 & 0.338 & 6.519 & 1 & 0.011 & 0.422 \\
\hline AllPct & -0.475 & 0.321 & 2.185 & 1 & 0.139 & 0.622 \\
\hline DefQ & -0.556 & 0.305 & 3.325 & 1 & 0.068 & 0.574 \\
\hline you & -1.018 & 0.364 & 7.823 & 1 & 0.005 & 0.361 \\
\hline ColonQ & -0.880 & 0.326 & 7.271 & 1 & 0.007 & 0.415 \\
\hline ApostroQ & 0.596 & 0.316 & 3.551 & 1 & 0.059 & 1.815 \\
\hline Law & 1.110 & 0.294 & 14.209 & 1 & 0.000 & 3.034 \\
\hline Constant & -1.903 & 0.379 & 25.269 & 1 & 0.000 & 0.149 \\
\hline
\end{tabular}

The model explains between 39 per cent and 57 per cent of the variance in CM (Cox and Snell $\mathrm{R}^{2}=0.39$; Nagelkerke $\mathrm{R}^{2}=0.57$ ). The Chi square of 63.89 with $\mathrm{df}$ $=9$ is significant $(\mathrm{p}=0.000)$, indicating that the independent variables have a significant effect on the dependent variable. The estimation sample classification accuracy is 88 per cent (baseline $=73$ per cent). Tenfold cross-validation was used to test the model. The results for all tenfolds were summed and yielded a classification accuracy of 82 per cent (sensitivity $=0.85$, specificity $=0.73$, Kappa $=0.55)$. Thus, on measures of classification accuracy the model is efficient. Variance inflation factors were between 1.38 (AllPct) and 1.09 (feelQ), with an average for all nine variables of 1.17 , indicating that there was no evidence of multi-collinearity.

From the above summary it is clear that the model is efficient at classifying members of the Coalition cohort and that all the variables are likely to be very useful in explaining why some people become CMs while others do not. In particular, the specificity - that is, the ability of the model to predict who is likely to become a $\mathrm{CM}$ - is 0.73 . The specificities of the Coalition representational models in the first section above were 0.25 for Coalition model one and 0.26 for Coalition model two. Thus, the ability of the cognitive model to predict who will be a CM is approximately three times greater than that of the model based on representational factors. To sum up the predictive accuracy of the model, using their maiden speech and information about an individual's legal training is enough to determine whether a new entrant to Parliament will or will not become a CM with approximately 80 per cent accuracy. 


\section{The ALP Model}

Several of the variables in the ALP model are also in the Coalition model.

- Legal education: in the ALP model, as in the Coalition model, this variable is significantly positively associated with CM. Also in common with the Coalition model is that fact that, of all the variables in the model, this has the strongest influence on CM.

- Spatial words: in the ALP model spatial term use is positively associated with CM. It is interesting to note that this is the opposite of the sign for the same variable in the Coalition model.

- Certainty words: in the ALP model, the use of certainty terms is positively associated with CM. Interestingly, this variable, like spatial term use, has the opposite sign in the Coalition model.

- Apostrophe occurrence: in the ALP model, as with the Coalition model, this variable is significantly positively associated with CM.

Table 3.5 Parameter Estimates for Variables in the ALP Cabinet Logistic Regression Model

\begin{tabular}{|c|c|c|c|c|c|c|}
\hline & B & S.E. & Wald & df & Sig. & Exp(B) \\
\hline Legal & 1.737 & 0.501 & 12.035 & 1 & 0.001 & 5.680 \\
\hline adverb & 1.572 & 0.517 & 9.240 & 1 & 0.002 & 4.815 \\
\hline conj & -1.465 & 0.501 & 8.538 & 1 & 0.003 & 0.231 \\
\hline space & 1.590 & 0.560 & 8.067 & 1 & 0.005 & 4.902 \\
\hline certainQ & 1.137 & 0.453 & 6.312 & 1 & 0.012 & 3.118 \\
\hline ApostroQ & 1.317 & 0.489 & 7.245 & 1 & 0.007 & 3.733 \\
\hline Constant & -0.753 & 0.383 & 3.864 & 1 & 0.049 & 0.471 \\
\hline
\end{tabular}

Notes: All variables are significant at the $\mathrm{p}<0.01$ level, except certainQ, which is significant at the $\mathrm{p}<$ 0.05 level. All variables are positively associated with CM except conj.

The model explains between 51 per cent and 69 per cent of the variance in CM (Cox and Snell $\mathrm{R}^{2}=0.51$; Nagelkerke $\mathrm{R}^{2}=0.69$ ). The Chi square of 58.6 with $\mathrm{df}$ $=6$ is significant $(\mathrm{p}=0.000)$, indicating that the independent variables have a significant effect on the dependent variable. The estimation sample classification accuracy is 89 per cent (baseline $=58.5$ per cent). Tenfold cross-validation was used to test the model. The results for all tenfolds were summed and yielded a classification accuracy of 80 per cent (sensitivity $=0.83$, specificity $=0.76$, Kappa $=0.59$ ). Thus, on measures of classification accuracy the model is efficient. Variance inflation factors were between 1.35 (conj) and 1.04 (apostroQ), with an average for all six variables of 1.22, indicating that there was no evidence of multi-collinearity. 
From the above summary it is clear that the model is efficient at classifying members of the ALP cohort and that all variables are likely to be very useful in explaining why some people become CMs while others do not. In particular, the sensitivity of 0.76 demonstrates that the cognitive model is significantly more accurate at detecting who will be a CM than the representational models (ALP model one sensitivity $=0.19$; ALP model two sensitivity $=0.25$ ). Again, with this approach we can determine whether a new entrant to Parliament will or will not become a CM with approximately 80 per cent accuracy.

\section{How Do We Explain These Results?}

The cognitive model provides a very convincing argument for the proposition that the individual cognitive characteristics of parliamentarians are what determine who will and who will not be appointed to cabinet. There has always been speculation that this was the case. Commentators often refer to 'talent' as being important but this is the first time anything akin to talent has been used to try to predict who will become a CM.

Although it is not an objective of this chapter to explain the specific influence of each of these variables on the dependent variable, it is worthwhile to briefly consider what may be going on. There are 11 different variables in the two models. Rather than attempting to account for all these variables, I give some general indications of the kind of influences that cognitive variables can have on cabinet appointments. Accordingly, I focus on the variables that are common to both models.

\section{Legal Education}

The positive influence of a legal education on the odds of an individual being appointed to cabinet has been noted in both parties. One can speculate as to why those with a legal education think differently from those without. One plausible explanation is that the mode of thinking that lawyers need to learn is akin to the mode of thinking involved in the work undertaken by a CM. There is some evidence that the mind-set of lawyers is something that is learnt. Christensen (2006) describes how high-achieving individuals who enrol in the law find it very difficult at first to adapt to the kind of thinking required to understand legal argument. These students in general perform well on verbal ability tests and yet have considerable difficulty in their early encounters with legal reasoning. By the end of their first year, most students have acquired the skill.

Miller (1995) has gathered a significant body of evidence indicating that lawyers in the US Congress are different from non-lawyers. As might be expected, one 
area in which lawyers have an advantage is the drafting of legislation (Miller 1995, 77). Legally trained members of the legislature are particularly useful in detecting technical defects in bills. Non-lawyers are more likely to defer to the judgment of their lawyer colleagues on such legal matters (Blaustein and Porter 1954, 99-100, cited in Miller 1995, 77). Non-lawyers are more likely to leave the consideration of constitutional issues to the courts. Furthermore, the technical aspects of law-making are more likely to be attended to by lawyers than non-lawyers (Morgan 1966, 156-57, 343-44, 366, cited in Miller 1995, 77). According to Miller, '[t]hese differences are subtle, but extremely important' (Miller 1995, 77).

\section{Spatial Terms}

The use of spatial terms was significant in both the Coalition and the ALP models although the effect was negative in the former and positive in the latter. The use of spatial terms has been found to be correlated with a propensity for expressing thought as opposed to affect (Marsh et al. 2005). What this implies is that members of the Coalition who express affect are more likely to become CMs while members of the ALP who express thought are more likely to become CMs. This is consistent with some of the research on the differences in ideological outlook. Skitka and Tetlock (1993), for example, find that liberals are more likely to want to help all claimants for welfare assistance whereas conservatives tend to want to withhold assistance from claimants who are responsible for their plight. In the case of the liberals, the decision is arrived at via a relatively sophisticated realisation that it is difficult to trade off the value of welfare in monetary terms. Thus it is a 'thoughtful moral judgment' rather than an 'ideological reflex' (Skitka and Tetlock 1993, 1212). In the case of the conservatives it is a more punitive - that is, affect-laden - process. What this indicates is that the strongly factual and analytical aspects of liberal thinking are valued in the ALP. The more affective characteristics are valued in the Coalition. These characteristics aid the promotion of individuals in their respective parties.

\section{Certainty Words}

We saw that in the ALP those who use more certainty words are more likely to become CMs while those in the Coalition who used certainty words are less likely to become CMs. What cognitive or behavioural characteristic is detected by certainty words? Fast and Funder (2008) found in a laboratory setting that subjects who use comparatively more certainty words are more likely to be judged by themselves, acquaintances and third parties unknown to the subjects as being more verbally and gesturally fluent and more socially adept than those who use fewer certainty words. The study used assessments 
by the subject and two of the subject's acquaintances on numerous 'microlevel' personality and behavioural characteristics such as 'is introspective', 'engages with the conversational partner' and 'is aloof'. Thus we have good

evidence that certainty word use is associated with some aspect of personality linked to gestural and verbal fluency, which facilitates social interaction. The interesting question is why this characteristic should be advantageous for the ALP parliamentarian and disadvantageous for the Coalition parliamentarian. One possibility is that persuasion is acceptable in a traditionally workingclass party whereas in a conservative party it could be seen as an attempt to subvert the existing hierarchy. The plausibility of this account is strengthened if we consider the number of leaders of conservative parties who have been considered uncharismatic speakers: John Gorton, Billy McMahon, Joh BjelkePetersen and Tim Fischer. John Howard merited the dismissive verdict: 'There is little to remember him by in his public utterances' (Errington and Onselen 2007, i); while another commentator observed that Howard's speech contains 'no cadence, no poetry, no elegance of language' (Adams 2000, 15). It is difficult to imagine such individuals becoming leaders in the ALP where a premium is placed on charisma. Gough Whitlam, Paul Keating and Bob Hawke were reported to be highly charismatic speakers. It is possible that, given the fundamental cognitive differences between conservatives and liberals (Carney et al. 2008) that seem to have a neuro-cognitive basis (Amodio et al. 2007), being charismatic is an advantage for the aspiring ALP CM but disadvantageous to their Coalition counterpart because conservatives see charisma as impolite.

\section{Apostrophe Occurrence}

Apostrophe occurrence (AO) is positively associated with CM in both models. In the text samples the majority of apostrophes is used either as the genitive marker or to indicate quotations. Inspection of the texts indicates that significantly fewer apostrophes are used to mark contractions. The apostrophe is therefore a proxy for references to and recognition of the authority of third parties. The positive association between apostrophe occurrence and being a CM is therefore somehow related to the focus of CMs on third parties. One only quotes another if one considers the other as being more authoritative. Thus, it is possible that AO taps into some measure of humility. The idea here is that the central notion of humility is exemplified by an individual's realisation that she has both strengths and weaknesses, can learn from others and that there is something greater than the self (Morris et al. 2005, 1331). Such an individual is very likely to be deferential to others, as she is aware that they have information and attitudes that she can use to improve her understanding of the world. Humble 'individuals appreciate that they do not have all the answers and, as a result, actively seek out the contributions of others as a means of overcoming their individual limitations' (Morris et al. 2005, 1332). 
There is clearly a role for humility in any group situation given that a leader has to be receptive to information and adapt to it. Those who have high opinions of themselves tend to be unable to adapt to information that does not support their self-view (Bushman and Baumeister 1998; Heatherton and Vohs 2000). Furthermore, there is evidence that those with high self-esteem are likely to be more irritating and belligerent towards others (Colvin et al. 1995).

Humility seems to be the antithesis of narcissism. The essential difference between the humble and the narcissistic person is that the former is involved in a process of comparing himself with the larger context whereas the latter is locked into a 'what about me' framework (Coutou 2004, cited in Morris et al. 2005, 1335). Typically, the narcissist is only interested in activities that outwardly promote their own glorification, and is therefore less adept at completing mundane tasks (Wallis and Baumeister 2002, cited in Morris et al. 2005, 1334).

This general overview of the variables common to each model demonstrates that there are highly plausible explanations as to why cognitive variables might have predictive power. It is likely that the predictive power of the variables I have not discussed is because they tap into some cognitive characteristic that is beneficial in a parliamentarian's attempt to become a CM.

\section{Conclusion}

The purpose of this chapter has been to demonstrate the efficacy of the cognitive model of $\mathrm{CM}$ selection. It began by demonstrating that the standard explanation for $\mathrm{CM}$ selection was highly inefficient. It then demonstrated with a cross-sectional model of the Coalition involving five cross-sections and 610 observations that only 25-26 per cent of cabinet appointments could be explained by using the standard representational variables. Similar results were found for a cross-section of the ALP in opposition.

Having concluded that the representational model is inadequate, a model was developed that focused on the cognitive characteristics of parliamentarians. Using one educational and eight linguistic variables, we can predict who would become a CM with an accuracy of approximately 80 per cent. Similar results were found for an ALP model based on one educational and five linguistic variables. This indicates very strongly that cognitive measures are highly predictive of the likelihood of being appointed to cabinet. I have not attempted to explain in detail the reasons for the relationships between the variables and the outcome; further research is likely to cast light on the precise nature of the processes at work. 


\section{References}

Adams, D. 2000. 'John Howard: Never Great, Always Adequate'. In The Howard Government: Australian Commonwealth Administration 1996-1998, ed. G. Singleton, pp. 13-25. Sydney: UNSW Press.

Amodio, D. M., J. T. Jost, S. L. Master and C. M. Yee. 2007. 'Neurocognitive Correlates of Liberalism and Conservatism'. Nature Neuroscience 10(10): $1246-7$.

Blaustein, A. P. and C. O. Porter. 1954. The American Lawyer: A Summary of the Survey of the Legal Profession. Chicago: University of Chicago Press.

Bushman, B. and R. Baumeister. 1998. 'Threatened Egotism, Narcissism, SelfEsteem, and Direct and Displaced Aggression: Does Self-Love or Self-Hate Lead to Violence?'. Journal of Personality and Social Psychology 75(1): 219-29.

Carney, D. R., J. T. Jost, S. D. Gosling and J. Potter. 2008. 'The Secret Lives of Liberals and Conservatives: Personality Profiles, Interaction Styles, and the Things They Leave Behind'. Political Psychology 29(6): 807-40.

Christensen, L. M. 2006. 'The Psychology behind Case Briefing: A Powerful Cognitive Schema'. Campbell Law Review 29(1): 303-23.

Clark, J. M. and A. Paivio. 2004. 'Extensions of the Paivio, Yuille, and Madigan (1968) Norms'. Behavior Research Methods, Instruments, and Computers 36(3): 371-83.

Colvin, C. R., J. Block and D. C. Funder. 1995. 'Overly Positive Self-Evaluations and Personality: Negative Implications for Mental Health'. Journal of Personality and Social Psychology 68(6): 1152-62.

Coutou, D. 2004. 'Putting Leaders on the Couch. A Conversation with Manfred F. R. Kets de Vries'. Harvard Business Review 82(1): 65-71.

Emrich, C., H. Brower, J. Feldman and H. Garner. 2001. 'Images in Words: Presidential Rhetoric, Charisma, and Greatness'. Administrative Science Quarterly 46(3): 527-57.

Errington, W. and P. van Onselen. 2007. John Winston Howard: The Biography. Melbourne: Melbourne University Press.

Fast, L. A. and D. C. Funder. 2008. 'Personality as Manifest in Word Use: Correlations with Self-Report, Acquaintance Report, and Behavior'. Journal of Personality and Social Psychology 94(2): 334-46. 
Heatherton, T. F. and K. D. Vohs. 2000. 'Interpersonal Evaluations Following Threats to Self: Role of Self-Esteem, Personality Processes and Individual Differences'. Journal of Personality and Social Psychology 78(4): 725-36.

Herman, M. 2003. 'Saddam Hussein's Leadership Style'. In The Psychological Assessment of Political Leaders: With Profiles of Saddam Hussein, ed. J. M. Post, pp. 375-86. Ann Arbor, Mich.: University of Michigan Press.

Hirst, G., Y. Riabinin and J. Graham. 2010. ‘Party Status as a Confound in the Automatic Classification of Political Speech by Ideology'. In Proceedings of 10th International Conference Journées d'Analyse Statistique des Données Textuelles, 9-11 June 2010, eds S. B. Isabella and C. L. Giuliano, pp. 731-42. Rome: Sapienza University of Rome.

House, R. J., W. D. Spangler and J. Woycke. 1991. 'Personality and Charisma in the US Presidency: A Psychological Theory of Leader Effectiveness'. Administrative Science Quarterly 36(3): 364-96.

Marsh, E. J., B. Tversky and M. Hutson. 2005. 'How Eyewitnesses Talk about Events: Implications for Memory'. Applied Cognitive Psychology 19(5): 53144.

Martindale, C. and A. Dailey. 1996. 'Creativity, Primary Process Cognition and Personality'. Personality and Individual Differences 20(4): 409-14.

Miller, M. C. 1995. The High Priests of American Politics: The Role of Lawyers in American Political Institutions. Knoxville: University of Tennessee Press.

Morgan, D. 1966. Congress and the Constitution: A Study of Responsibility. Cambridge, Mass.: Belknap Press of Harvard University Press.

Morris, J., C. M. Brotheridge and J. C. Urbanski. 2005. 'Bringing Humility to Leadership: Antecedents and Consequences of Leader Humility'. Human Relations 58(10): 1323-50.

Niederhoffer, K. G. and J. W. Pennebaker. 2002. 'Linguistic Style Matching in Social Interaction'. Journal of Language and Social Psychology 21(4): 337-60.

Paivio, A., J. C. Yuille and S. A. Madigan. 1968. 'Concreteness, Imagery and Meaningfulness Values for 925 Words'. Journal of Experimental Psychology 76(1): 1-25.

Pennebaker, J. W. and L. A. King. 1999. 'Linguistic Styles: Language Use as an Individual Difference'. Journal of Personality and Social Psychology 77(6): 1296-312. 
Pennebaker, J. W., C. K. Chung, M. Ireland, A. Gonzales and R. J. Booth. 2007. The Development and Psychometric Properties of LIWC 2007. Austin, Tex.: LIWC.net.

Skitka, L. J. and P. E. Tetlock. 1993. 'Providing Public Assistance: Cognitive and Motivational Processes Underlying Liberal and Conservative Policy Preferences'. Journal of Personality and Social Psychology 65(6): 1205-23.

Suedfeld, P. and A. D. Rank. 1976. 'Revolutionary Leaders: Long-Term Success as a Function of Changes in Conceptual Complexity'. Journal of Personality and Social Psychology 34(2): 169-78.

Tausczik, Y. R. and J. W. Pennebaker. 2010. 'The Psychological Meaning of Words: LIWC and Computerized Text Analysis Methods'. Journal of Language and Social Psychology 29(1): 24-54.

Wallis, H. M. and R. F. Baumeister. 2002. 'The Performance of Narcissists Rises and Falls with Perceived Opportunity for Glory'. Journal of Personality and Social Psychology 82(5): 819-34.

Watson, D., L. A. Clark and A. Tellegen. 1988. 'Development and Validation of Brief Measures of Positive and Negative Affect: The PANAS Scales'. Journal of Personality and Social Psychology 54(6): 1063-70.

West, A., C. Martindale, D. Hines and W. T. Roth. 1983. 'Marijuana-Induced Primary Process Content in the TAT'. Journal of Personality Assessment 47(5): 466-7.

Winter, D. G. 1987. 'Leader Appeal, Leader Performance, and the Motives Profile of Leaders and Followers: A Study of American Presidents and Elections'. Journal of Personality and Social Psychology 52(1): 96-202.

Yu, B., S. Kaufman and D. Diermeier. 2008. 'Classifying Party Affiliation from Political Speech'. Journal of Information Technology \& Politics 5(1): 33-48. 


\section{Appendix 3.1}

\section{Coalition Representational Model}

The model discussed in Appendix 3.1 was created using a repeated measures design with the individual as the subject effect and the cross-section year as the within-subject effect.

The variables included were

- age

- age squared

- experience

- experience squared

- States (Victoria, Queensland, South Australia, Western Australia, Tasmania); New South Wales is the reference category

- gender

- party (Liberal Party/National Party)

- house (HOR/Senate).

The Territories Australian Capital Territory and Northern Territory were excluded because no ministers were drawn from these locations and they are therefore redundant levels in the model.

Table A3.1 Coalition Representational Model Parameter Estimates

\begin{tabular}{|c|c|c|c|c|c|c|c|}
\hline \multirow{2}{*}{ Parameter } & \multirow[b]{2}{*}{ B } & \multirow[b]{2}{*}{ Std error } & \multicolumn{2}{|c|}{ Confidence interval } & \multicolumn{3}{|c|}{ Hypothesis test } \\
\hline & & & Lower & Upper & $\begin{array}{l}\text { Wald Chi- } \\
\text { square }\end{array}$ & df & Sig. \\
\hline (Intercept) & -21.579 & 5.8029 & -32.953 & -10.206 & 13.829 & 1 & 0.000 \\
\hline$[N P=1]$ & -0.265 & 0.5559 & -1.354 & 0.824 & 0.227 & 1 & 0.634 \\
\hline$[N P=0]$ & $\mathrm{O}^{\mathrm{a}}$ & . & . & . & . & $\cdot$ & . \\
\hline$[$ Senate $=1]$ & -0.403 & -0.4927 & -1.369 & 0.562 & 0.670 & 1 & 0.413 \\
\hline$[$ Senate $=0]$ & $0^{a}$ & . & . & . & . &. & . \\
\hline$[$ Female $=1]$ & -0.688 & 0.5410 & -1.748 & 0.373 & 1.615 & 1 & 0.204 \\
\hline$[$ Female $=0]$ & $0^{a}$ & . & . & . & . &. & . \\
\hline [Vic. = 1] & -0.728 & 0.5674 & -1.840 & 0.384 & 1.645 & 1 & 0.200 \\
\hline [Vic. = 0] & $\mathrm{O}^{\mathrm{a}}$ & . & . & . & . & $\cdot$ & . \\
\hline$[\mathrm{Qld}=1]$ & -1.423 & 0.6950 & -2.785 & -0.061 & 4.193 & 1 & 0.041 \\
\hline$[$ Qld $=0]$ & $0^{a}$ & . & . & . & . & $\cdot$ & . \\
\hline [Tas. = 1] & -1.139 & 1.3174 & -3.721 & 1.443 & 0.747 & 1 & 0.387 \\
\hline$[$ Tas. $=0]$ & $\mathrm{O}^{\mathrm{a}}$ & . & . & . & . & . & . \\
\hline
\end{tabular}




\begin{tabular}{|c|c|c|c|c|c|c|c|}
\hline \multirow[b]{2}{*}{ Parameter } & \multirow[b]{2}{*}{ B } & \multirow[b]{2}{*}{ Std error } & \multicolumn{2}{|c|}{ Confidence interval } & \multicolumn{3}{|c|}{ Hypothesis test } \\
\hline & & & Lower & Upper & $\begin{array}{l}\text { Wald Chi- } \\
\text { square }\end{array}$ & $d f$ & Sig. \\
\hline$[S A=1]$ & -0.443 & 0.6605 & -1.738 & 0.851 & 0.451 & 1 & 0.502 \\
\hline$[S A=0]$ & $\mathrm{O}^{\mathrm{a}}$ & & . & . & . & . & . \\
\hline$[\mathrm{WA}=1]$ & -1.241 & 0.8007 & -2.810 & 0.329 & 2.400 & 1 & 0.121 \\
\hline$[W A=0]$ & $\mathrm{O}^{\mathrm{a}}$ & & . & . & . & . & . \\
\hline Age & 0.798 & 0.2343 & 0.339 & 1.257 & 11.595 & 1 & 0.001 \\
\hline $\mathrm{Age}^{2}$ & -0.008 & 0.0023 & -0.013 & -0.004 & 13.910 & 1 & 0.000 \\
\hline Exp. & 0.314 & 0.0845 & 0.148 & 0.479 & 13.774 & 1 & 0.000 \\
\hline Exp. $^{2}$ & -0.005 & 0.0029 & -0.011 & 0.001 & 3.011 & 1 & 0.083 \\
\hline
\end{tabular}

\section{Appendix 3.2}

\section{ALP Representational Model}

The model discussed in Appendix 3.2 was created using a repeated measures design with the individual as the subject effect and the cross-section year as the within-subject effect.

The Territories Australian Capital Territory and Northern Territory were excluded because no ministers were drawn from these locations and they are therefore redundant levels in the model.

\section{ALP Representational Model}

Variables included

- age

- age squared

- experience

- experience squared

- States (Victoria, Queensland, South Australia, Western Australia, Tasmania); New South Wales is the reference category

- gender

- house (HOR/Senate). 
3. Predicting Cabinet Ministers: A psychological approach

Table A3.2 ALP Representational Model Parameter Estimates

\begin{tabular}{|c|c|c|c|c|c|c|c|}
\hline \multirow[b]{2}{*}{ Parameter } & \multirow[b]{2}{*}{ B } & \multirow[b]{2}{*}{ Std error } & \multicolumn{2}{|c|}{ Confidence interval } & \multicolumn{3}{|c|}{ Hypothesis test } \\
\hline & & & Lower & Upper & $\begin{array}{l}\text { Wald Chi- } \\
\text { square }\end{array}$ & df & Sig. \\
\hline (Intercept) & -23.947 & 17.6200 & -58.481 & 10.588 & 1.847 & 1 & 0.174 \\
\hline$[$ Senate $=1]$ & -0.585 & 0.6234 & -1.807 & 0.636 & 0.882 & 1 & 0.348 \\
\hline$[$ Senate $=0]$ & $0^{a}$ & . & . & . & . & . & . \\
\hline$[$ Female $=1]$ & 0.177 & 0.8169 & -1.424 & 1.778 & 0.047 & 1 & 0.828 \\
\hline$[$ Female $=0$ ] & $\mathrm{O}^{\mathrm{a}}$ & . & . & . & . & . & . \\
\hline [Vic. = 1] & 1.092 & 0.7694 & -0.416 & 2.600 & 2.016 & 1 & 0.156 \\
\hline [Vic. = 0] & $0^{a}$ & . & . & . & . & . & . \\
\hline [Qld = 1] & 0.304 & 1.1772 & -2.003 & 2.612 & 0.067 & 1 & 0.796 \\
\hline [Qld = 0] & $0^{a}$ & . & . & . & . & . & . \\
\hline$[$ Tas. $=1]$ & 0.281 & 1.0534 & -1.784 & 2.345 & 0.071 & 1 & 0.790 \\
\hline$[$ Tas. $=0]$ & $0^{a}$ & . & . & . & . & . & . \\
\hline$[S A=1]$ & 2.613 & 1.5388 & -0.403 & 5.629 & 2.882 & 1 & 0.090 \\
\hline$[S A=0]$ & $0^{a}$ & . & . & . & . & . & . \\
\hline$[W A=1]$ & 1.727 & 0.8712 & 0.019 & 3.434 & 3.929 & 1 & 0.047 \\
\hline$[W A=0]$ & $\mathrm{O}^{\mathrm{a}}$ & . & . & . & . & . & . \\
\hline$[L=1]$ & -0.529 & 0.6691 & -1.840 & 0.782 & 0.625 & 1 & 0.429 \\
\hline$[L=0]$ & $0^{a}$ & . & . & . & . & . & . \\
\hline$[\mathrm{Cl}=1]$ & -0.606 & 1.0306 & -2.626 & 1.414 & 0.346 & 1 & 0.556 \\
\hline$[\mathrm{Cl}=0]$ & $\mathrm{O}^{\mathrm{a}}$ & . & . & . & . & . & . \\
\hline Age & 0.932 & 0.7268 & -0.492 & 2.357 & 1.645 & 1 & 0.200 \\
\hline $\mathrm{Age}^{2}$ & -0.012 & 0.0075 & -0.026 & 0.003 & 2.379 & 1 & 0.123 \\
\hline Exp. & 0.768 & 0.2498 & 0.279 & 1.258 & 9.462 & 1 & 0.002 \\
\hline Exp. ${ }^{2}$ & -0.022 & 0.0108 & -0.043 & -0.001 & 4.112 & 1 & 0.043 \\
\hline
\end{tabular}

